\title{
A New Journal Serving the Infrasound Community
}

\author{
Michael A. H. Hedlin \\ Laboratory for Atmospheric Acoustics, University of California, San Diego, USA \\ Email: hedlin@ucsd.edu
}

Received August 20, 2013; revised September 21, 2013; accepted September 29, 2013

Copyright (c) 2013 Michael A. H. Hedlin. This is an open access article distributed under the Creative Commons Attribution License, which permits unrestricted use, distribution, and reproduction in any medium, provided the original work is properly cited.

InfraMatics is an international peer-reviewed journal dedicated to presenting observational and theoretical studies of atmospheric infrasound generation, propagation, and reception that address outstanding problems in basic and applied research. Under the auspices of Scientific Research Publishing (SCIRP) three issues of InfraMatics have been published since the refereed journal was introduced in 2012. These issues can be found at http:// www.scirp.org/journal/inframatics. To date over 1500 copies of these issues have been downloaded and there have been a total of over 20,000 visits to the site.

In 1883, the Krakatoa volcano awakened the world to the existence of sub audible sound waves in the atmosphere. These waves, known as infrasound, can travel thousands of kilometers and are readily detected by sensitive microbarometers. We now know that a wide variety of other naturally-occurring phenomena such as tornadoes, landslides, earthquakes, meteors, aurora, atmospheric turbulence, and interacting waves on the surface of the ocean also generate infrasound. In addition, infrasound is also generated by a large number of man-made sources including nuclear and chemical explosions, rockets and supersonic aircraft. These long-period sound waves were of great interest in the 1950's and 1960's during the era of atmospheric nuclear testing. Interest waned as the Limited Test-Ban Treaty pushed nuclear testing underground. The Comprehensive Nuclear TestBan Treaty rekindled interest, however. This treaty bans all nuclear tests and establishes a monitoring network of sensors that probe the Earth's solid interior, oceans and atmosphere for unusual signals. The infrasound network will offer us an unprecedented opportunity to better understand man-made and natural atmospheric phenomena on a global scale. The global network is enhanced in some regions by other infrasound arrays and, notably, in the United States by the Transportable Array [1] that comprises 400 combined seismic and acoustic stations on a Cartesian grid spanning 2,000,000 $\mathrm{km}^{2}$. We anticipate that the global network of listening posts that monitor the Earth's atmospheric shell will some day become as indispensable as the global seismic network that monitors
Earth's solid interior. There have been some noteworthy events recorded recently by these stations including the meteor that entered the Earth's atmosphere above Chelyabinsk Russia in February, 2013. Signals from this event were recorded by infrasound arrays after circling the globe twice [2] and by the Transportable Array. Another recent event that was recorded by a large number of infrasound stations was the eruption of Eyjafjallajökull, Iceland [3].

InfraMatics is one of the journals sponsored by the Scientific Research Publishing group headquartered in Wuhan, China. It is the first and currently the only specialty journal in the field of infrasound. It was launched under the philosophy of free sharing and use of scientific information. This open-access online journal has a worldwide representative panel of editorial board members, who, together with external reviewers, carry out vigorous and fair evaluation of each submitted manuscript. The journal welcomes research on natural and anthropogenic sources of infrasound in the atmosphere, oceans, or below the Earth's surface, as well as studies of wave coupling and interactions, data metrics, data analysis methods, instrumentation and standards. Topics of interest include, but are not limited to:

- Infrasound data analysis methods;

- Infrasound data metrics;

- Infrasound sensors;

- Background noise reduction;

- Infrasound standards;

- Observational and theoretical studies of infrasound generation, propagation and reception;

- Studies of natural and anthropogenic sources of infrasound;

- Studies of wave coupling and interactions. The journal will also publish:

1) Short reports-2 - 5 page papers where an author can present preliminary data or theoretical results before completing the research needed for a complete paper;

2) Infrasound event reports.

InfraMatics charges a very affordable publication fee for accepted papers, and manuscripts in all aspects of 
infrasound are considered for publication. This journal is currently indexed by a number of world-class databases/ searching engines including CrossRef and Google Scholar (http://www.scirp.org/journal/inframatics).

The editorial team and publisher anticipate a healthy growth of this journal in the future. As a part of increased interest in infrasound, InfraMatics seeks to serve a unique and important international platform for scientific communication in infrasound research.

\section{REFERENCES}

[1] R. W. Busby, F. L. Vernon, R. L. Newman and L. Astiz,
“Earth-Scope’s US Array: Advancing Eastward,” Eos Trans. AGU, Vol. 87, No. 52, 2006, Abstract U41B-0820.

[2] A. Le Pichon, L. Ceranna, C. Pilger, P. Mialle, D. Brown, P. Herry and N. Brachet, "The 2013 Russian Fireball Largest Ever Detected by CTBTO Infrasound Sensors," Geophysical Research Letters, Vol. 40, No. 14, 2013, pp. 3732-3737. doi:10.1002/grl.50619

[3] R. S. Matoza, et al., "Long-Range Acoustic Observations of the Eyjafjallajökull Eruption, Iceland, April-May 2010,” Geophysical Research Letters, Vol. 38, No. 6, 2011, Article ID: L06308. doi:10.1029/2011GL047019 